\title{
Uma Cidade para Poucos? Particularidades da produção da moradia para segmentos populares em Imperatriz-MA
}

\author{
A City for Few? Particularities of housing production for popular \\ segments in Imperatriz-MA
}

\section{¿Una Ciudad para Pocos? Particularidades de la producción de viviendas para segmentos populares en Imperatriz-MA}

\author{
Kaio de Moura Silva ${ }^{1}$ \\ https://orcid.org/0000-0002-0421-8256 \\ Jailson de Macedo Sousa ${ }^{2}$ \\ https://orcid.org/0000-0003-2138-6013 \\ Beatriz Ribeiro Soares ${ }^{3}$ \\ https://orcid.org/ 0000-0002-1377-6532
}

\begin{abstract}
RESUMO: Neste artigo, refletimos sobre as configurações da política habitacional difundida na cidade de Imperatriz, em particular no conjunto habitacional Itamar Guará, que se localiza na porção sul, em uma área periférica da cidade. Objetivou-se entender as relações entre o processo de expansão urbano e a problemática da segregação espacial urbana. Assim, este estudo apresenta como problemática central a questão da moradia e, no interior desta, as políticas habitacionais difundidas por meio do Programa Minha Casa Minha Vida - PMCMV, tendo como particularidade analítica a dinâmica da segregação socioespacial urbana, materializada no conjunto Itamar Guará. Para obtenção de dados foram realizadas entrevistas semiestruturadas com os/as moradores/as, baseadas na observação sistemática. Graves problemas arrolados na realidade do conjunto apontaram para a necessidade da realização de um estudo, a fim de entender os efeitos da política habitacional difundida nesta localidade. Desse modo, notou-se que a segregação socioespacial urbana constitui um dos ingredientes, ou seja, um dos efeitos da política habitacional, expressando-se através da ausência de políticas públicas educacionais, ausência de áreas verdes e ausência do saneamento básico, entre outros problemas.
\end{abstract}

PALAVRAS-CHAVE: Política habitacional. Segregação espacial urbana. Imperatriz-MA.

\footnotetext{
${ }^{1}$ Graduando em Geografia pela Universidade Estadual da Região Tocantina do Maranhão - UEMASUL. Email: kaiomsil18@gmail.com.

${ }^{2}$ Doutorado em Geografia pela Universidade Federal de Uberlândia. Professor da Universidade Estadual da Região Tocantina do Maranhão - UEMASUL. E-mail: geoparsagada@gmail.com.

3 Doutorado em Geografia Humana pela Universidade de São Paulo. Professora da Universidade Federal de Uberlândia. E-mail: brsoares@ufu.br.
} 
Uma Cidade para Poucos? Particularidades da produção da moradia para segmentos populares em...

ABSTRACT: In this article, we reflect on the configurations of the housing policy widespread in the city of Imperatriz, particularly in the Itamar Guará housing complex, which is located in the southern portion of the city, in a peripheral area. The objective was to understand the relationships between the process of urban expansion and the problem of urban spatial segregation. Thus, this study presents as a central problem the question of housing and, within this, the housing policies disseminated through the Program Minha Casa Minha Vida - PMCMV, having as analytical particularity, the dynamics of urban socio-spatial segregation, materialized in the Itamar Guará set. To obtain data, semi-structured interviews were conducted with the residents, based on systematic observation. Serious problems in the reality of the set pointed to the need for a study in order to understand the effects of the housing policy spread in this locality. Thus, it was noted that urban social-spatial segregation constitutes one of the ingredients, i.e., the effects of housing policy, expressing, through the absence of public educational policies, the absence of green areas, the absence of basic sanitation, among other problems.

KEYWORDS: Housing policy. Urban spatial segregation. Imperatriz-MA.

RESUMEN: En este artículo, reflexionamos sobre elementos esenciales de la reciente configuración de la política de vivienda difundida en la ciudad de Imperatriz. En este contexto, nos centramos en las relaciones de la expansión urbana con el problema de la segregación espacial urbana. El recorte espacial elegido es el complejo habitacional Itamar Guará I que se encuentra en la parte sur, en un área periférica de la ciudad de la Imperatriz. Así, este estudio se preocupó por reflexionar sobre los contenidos y significados de la política de vivienda contemporánea, difundida a través del Programa Minha Casa Minha Vida - PMCMV. El Itamar Guará I se implementó en esta ciudad en 2012 y denota serios problemas socio-espaciales, destacándose en este escenario: la mala calidad de la estructura de las casas, la falta de pavimento, la falta de escuelas para atender las demandas de la población, las áreas de esparcimiento y la seguridad pública, entre otros. Los problemas señalaron la necesidad de un estudio para comprender los efectos de la política de vivienda difundida en este lugar.

PALABRAS CLAVE: Política de vivenda. Segregación espacial urbana. Imperatriz-MA.

\section{INTRODUÇÃO}

A organização das cidades brasileiras apresenta como característica as intensas desigualdades sociais, cujos conteúdos revelam a problemática da segregação espacial urbana, denotando implicações nos seus processos, formas, conteúdos e estrutura. A urbanização no Brasil foi intensificada a partir da década de 1950, em virtude de múltiplos fatores, entre estes ressalta-se a difusão da atividade industrial, o intenso êxodo rural que induziu as massas populacionais de distintas regiões do país, sobretudo de regiões periféricas para o centro-sul e a modernização imposta pelo capital ao território.

O processo de urbanização difundido no Brasil promoveu, desde então, intensas mudanças em suas cidades implicando em novas formas e significados de habitação, sendo, pois, um elemento peculiar ao processo de urbanização que é típico de países periféricos. Neste cenário, urge identificar os atores que são responsáveis pelos processos de produção e reprodução do espaço urbano e a problemática que se materializa nas 
cidades brasileiras, uma vez que o intenso crescimento populacional registrado, sobretudo, nas metrópoles e cidades médias, apresenta-se intenso, complexo e heterogêneo.

É reconhecido que a cidade capitalista contemporânea revela como um dos seus traços singulares o diferencial de uso do solo urbano. Tal fato pode ser explicado em razão da apropriação desigual do espaço urbano pelos seus distintos agentes de produção. Corrêa (1989) destaca a necessidade de reconhecer esses agentes que são responsáveis pela produção e reprodução do espaço urbano, com destaque para os proprietários dos meios de produção, proprietários fundiários, promotores imobiliários, Estado e os grupos sociais excluídos, haja vista que são estes responsáveis pela produção e reprodução do espaço urbano e pelo dinamismo socioespacial materializado na cidade. Assim, cada um dos atores exerce funções distintas na formação, estruturação e reestruturação da cidade.

Os grupos sociais excluídos, por exemplo, como a própria terminologia expressa, são os que mais padecem neste processo, uma vez que têm o acesso aos bens e infraestrutura urbana negados, ou seja, Ihes são imputados o direito à cidade. É, pois, diante deste cenário a envolver a realidade social dos processos de produção e reprodução do espaço urbano que se justifica a importância desta pesquisa.

Para desenvolver a presente pesquisa foi necessário de início refletir e entender as particularidades do atual processo de produção do espaço urbano de Imperatriz, tendo como viés interpretativo a política habitacional contemporânea, materializada nesta cidade e que vem sendo orientada por meio do Programa Minha Casa, Minha Vida. O recorte espacial escolhido para esta interpretação é o conjunto habitacional Itamar Guará. Trata-se de um conjunto habitacional que foi implantado nesta cidade no ano de 2012, em uma área periférica.

Imperatriz é a segunda cidade mais importante do estado do Maranhão (figura 1), quando considerados os aspectos demográficos e econômicos, uma vez que o seu quantitativo populacional só é inferior a capital do estado, São Luís. O Instituto Brasileiro de Geografia e Estatísticas - IBGE (2019) sinalizou para o ano de 2019 um quantitativo total de 258.682 habitantes, sendo que destes $95 \%$ se concentram na sede municipal.

Imperatriz conheceu, desde 1950, intensos ritmos de crescimento populacional. O auge deste crescimento, conforme sinalizam os estudos de Sousa $(2009,2015,2018)$, ocorreu entre 1960-1980, motivado pelas estratégias de ocupação difundidas na Amazônia brasileira. Um fato legítimo que se apresenta como hipótese central deste estudo diz respeito à carência generalizada de equipamentos urbanos. Este fato constitui uma singularidade do urbano na Amazônia brasileira, conforme atestam estudos de Becker (1990, 2005, 2013).

Por meio deste artigo buscou-se compreender as particularidades do atual processo de urbanização materializado na cidade de Imperatriz, destacando como instrumento 
analítico, neste trajeto, os desdobramentos da política habitacional, orientada por meio do Programa Minha Casa Minha Vida, do Governo Federal. Procurou-se investigar, neste percurso analítico, os efeitos e os significados desta política, particularizando estas interpretações junto às populações de baixo poder aquisitivo, ou seja, as populações beneficiadas com a referida política e enquadradas na faixa um, segundo a definição dos órgãos executores do referido programa.

Figura 1 - Mapa de localização de Imperatriz no contexto da Amazônia Legal

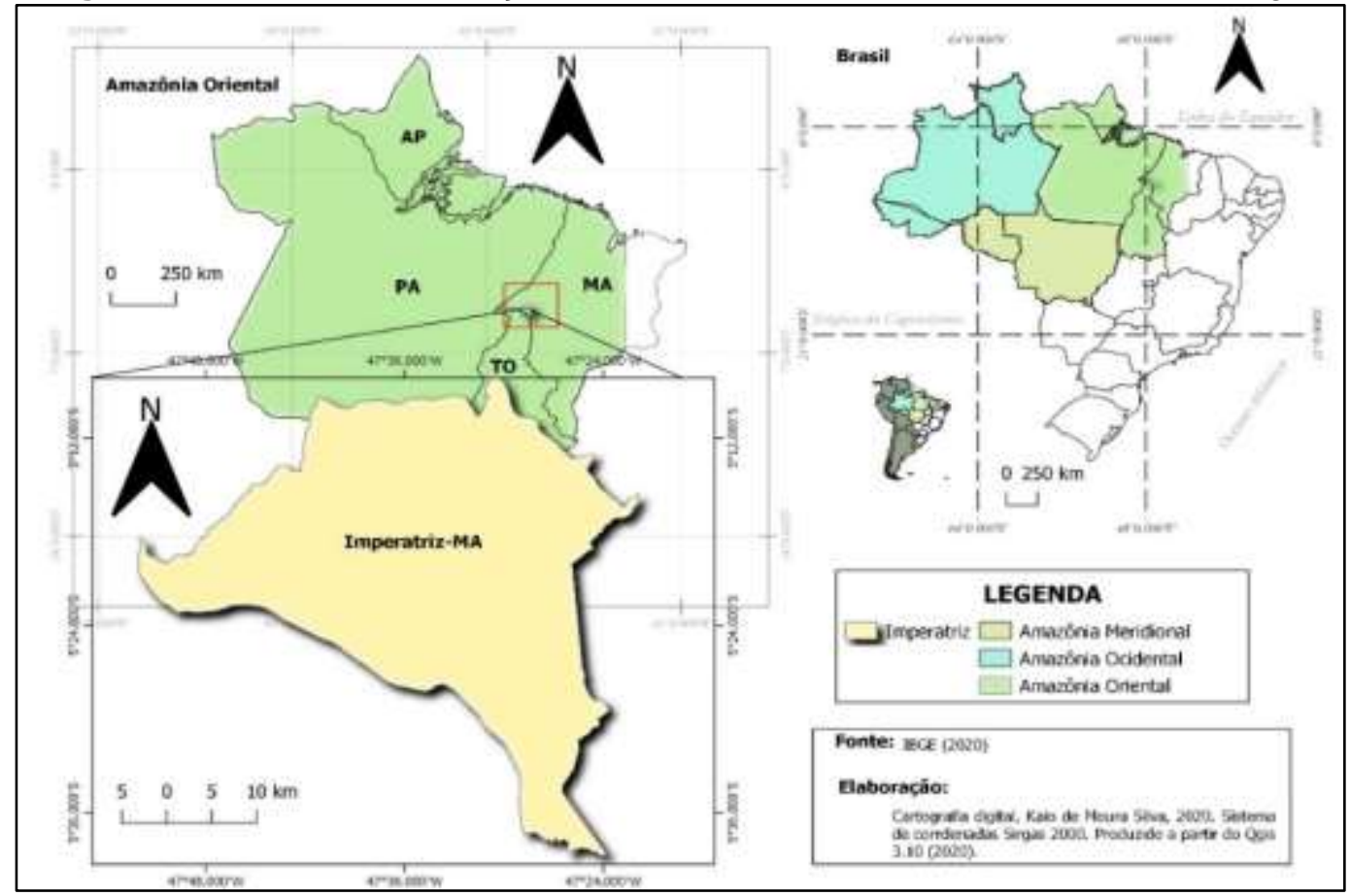

Fonte: Silva e Sousa (2019).

\section{PARTICULARIDADES DA URBANIZAÇÃO BRASILEIRA E A PROBLEMÁTICA DO DÉFICIT HABITACIONAL}

A compreensão dos processos que envolvem a problemática habitacional, em particular o déficit habitacional no Brasil, que também se faz presente na cidade de Imperatriz, requer, de início, uma breve reflexão acerca da evolução urbana brasileira.

É reconhecido que este fenômeno adquiriu maior notoriedade, tornando-se mais intenso e vigoroso após 1950. A tabela 1, a seguir, revela estes ritmos frenéticos, complexos e desiguais da urbanização brasileira, considerando o conjunto total de suas regiões.

Ao refletir e ponderar sobre os dados dispostos na tabela 1 confirma-se a afirmação de Santos (1996) que na obra "A urbanização brasileira" ressalta como elementos característicos desta a sua "complexidade e diversificação". Esta máxima pode ser explicada ao se observar o dinamismo assumido pela região Sudeste. Na década de 1950 esta região 
já superava os índices no âmbito nacional, concentrando $47,5 \%$ da população nas sedes municipais, enquanto que o índice registrado no país equivalia a 36,2\%. Em contrapartida, a região Nordeste contou, neste mesmo período, com uma participação de $25,4 \%$. Tais fatos confirmam as ideias difundidas por Santos (1996), que ressalta:

A complexa organização territorial e urbana do Brasil guarda profundas diferenças entre as suas regiões. Em 1980, é a região Sudeste, a mais urbanizada com índice de $82,8 \%$. A menos urbanizada é a região Nordeste, com $50,44 \%$ de urbanos, quando a taxa de urbanização do Brasil era de $65,57 \%$. [...] Mais recentemente, todas as áreas do país experimentaram um revigoramento do seu processo de urbanização, ainda que em níveis e formas diferentes, graças às diversas modalidades e impactos da modernização sobre o território (SANTOS, 1996, p. 57-64).

Tabela 1 - Evolução Regional da População Urbana no Brasil (1950-2010) - \%

\begin{tabular}{c|c|c|c|c|c|c}
\hline Ano & Brasil & Norte & Nordeste & $\begin{array}{c}\text { Centro } \\
\text { Oeste }\end{array}$ & Sul & Sudeste \\
\hline 1950 & 36,2 & 31,5 & 25,4 & 24,4 & 29,5 & 47,5 \\
\hline 1960 & 44,9 & 37,4 & 33,9 & 34,4 & 37,1 & 57,0 \\
\hline 1970 & 55,9 & 42,6 & 41,8 & 50,7 & 44,3 & 72,7 \\
\hline 1980 & 67,6 & 50,3 & 50,5 & 70,8 & 62,4 & 82,8 \\
\hline 1991 & 75,5 & 59,0 & 60,6 & 81,3 & 74,1 & 88,0 \\
\hline 2000 & 81,2 & 62,0 & 69,1 & 86,7 & 80,9 & 90,5 \\
\hline 2010 & 84,4 & 69,9 & 73,1 & 88,8 & 84,9 & 92,9 \\
\hline
\end{tabular}

Fonte: Silva e Sousa (2019).

Esta configuração complexa da urbanização brasileira é marcada por fortes diferenças. Um dos seus aspectos peculiares diz respeito à ausência do planejamento urbano. As cidades brasileiras, sobretudo as metrópoles e cidades médias cresceram velozmente, denotando padrões espaciais caóticos, cujas marcas revelam uma urbanização célere, dual e excludente. No bojo deste modelo dual de urbanização é que se revelam problemas sociais diversos, dentre os quais a problemática do déficit habitacional, que é foco desta pesquisa.

Trata-se de um problema crônico que se arrasta há mais de cinco séculos e demonstra a ineficácia do Estado em suas distintas esferas no que tange ao planejamento urbano. Nesse sentido, enfatizam-se, na tabela 2, os dados referentes ao déficit habitacional brasileiro, distribuído entre as suas grandes regiões, traduzindo um dos efeitos do crescimento urbano. Considerou-se, para efeitos de análise, o período corresponde aos anos de 2000 e 2015.

Os dados expostos na tabela 02 revelam que populações vivendo sem moradia e residindo em moradias precárias é bastante elevado no país, o quantitativo total alcançou 6.355.744 pessoas nessas condições, conforme atestam os estudos sistematizados pela Fundação João Pinheiro (2019). Estes dados estão fundamentados na metodologia utilizada 
Uma Cidade para Poucos? Particularidades da produção da moradia para segmentos populares em...

pela Fundação João Pinheiro (2013, 2019), que considera, para efeitos de análise, as pesquisas domiciliares realizadas pelo IBGE, por meio da Pesquisa Nacional por Amostra de Domicílios - PNAD e também os censos demográficos.

Tabela 2 - Evolução do déficit habitacional brasileiro por regiões (2000-2015)

\begin{tabular}{c|r|r|r|r}
\hline Regiões & $\begin{array}{c}\text { Déficit habitacional } \\
\mathbf{( 2 0 0 0 )}\end{array}$ & \multicolumn{1}{c|}{ Total \% } & $\begin{array}{c}\text { Déficit habitacional } \\
\mathbf{( 2 0 1 5 )}\end{array}$ & \multicolumn{1}{c}{ Total \% } \\
\hline Sudeste & 2.341 .698 & 32,42 & 2.482 .855 & 39,07 \\
\hline Nordeste & 2.851 .197 & 39,48 & 1.971 .856 & 31,02 \\
\hline Sul & 678.879 & 9,40 & 734.115 & 11,55 \\
\hline Norte & 848.696 & 11,75 & 645.537 & 10,16 \\
\hline Centro-Oeste & 502.175 & 6.95 & 521.381 & 8,2 \\
\hline BRASIL & $\mathbf{7 . 7 2 2 . 6 4 5}$ & $\mathbf{1 0 0 , 0}$ & $\mathbf{6 . 3 5 5 . 7 4 4}$ & $\mathbf{1 0 0 , 0}$ \\
\hline
\end{tabular}

Fonte: organizado pelos autores a partir de Fundação João Pinheiro (2019).

É reconhecido que, no ano de 2010, estas regiões contabilizaram respectivamente, um quantitativo de $32,42 \%$ (Sudeste) e $39,48 \%$ (Nordeste). O déficit habitacional nestas duas regiões, no ano de 2015 , foram para $39,07 \%$ e $31,02 \%$. Com isso, infere-se que ambas responderam neste período recente por $70,09 \%$ do déficit habitacional do país.

A ausência de moradias ou a presença de pessoas residindo em moradias precárias constitui um conteúdo que é peculiar à realidade urbana brasileira, embora assuma particularidades nas regiões do país, conforme pôde-se notar na tabela 2. O Brasil, a exemplo de outros países latino-americanos, como é o caso da Argentina e do México, conheceu célere e vigoroso processo de urbanização, tendo como motivação a intensificação da divisão territorial do trabalho. No entanto, este crescimento da população não foi acompanhado de políticas sociais eficazes no seu tecido urbano (SANTOS; SILVEIRA, 2011).

Neste cenário, a região Nordeste, por concentrar a segunda maior proporção do déficit habitacional do país, retrata esta ausência do planejamento urbano e o intenso déficit habitacional. O estado do Maranhão não tem fugido deste dinamismo, uma vez que denota elevada proporção de sua população convivendo com o problema do déficit habitacional.

\section{POLÍTICAS HABITACIONAIS NO BRASIL CONTEMPORÂNEO: NOVAS DEMANDAS PARA VELHAS POLÍTICAS?}

Diante do reconhecimento dos elevados índices do déficit habitacional presente nas distintas regiões do país, as políticas habitacionais tornaram-se essenciais à organização do espaço urbano, sendo entendidas como vitais para a distribuição equânime de moradias.

É reconhecido que é somente a partir da década de 1960, ou seja, particularmente no ano de 1964 que as ações desenvolvidas em âmbito federal adquiriram notoriedade. Desde 
então, as políticas habitacionais passaram a ter maior visibilidade no território brasileiro. Nesses termos, o Ministério das Cidades enfatiza:

O modelo de política habitacional implementado a partir de 1964, pelo Banco Nacional de Habitação (BNH), baseava-se em características que deixaram marcas importantes na estrutura institucional e na concepção dominante de política habitacional nos anos que se seguiram. [...] podem ser identificadas a partir dos seguintes elementos: primeiro, a criação de um sistema de financiamento que permitiu a captação de recursos específicos e subsidiados, o Fundo de Garantia de Tempo de Serviço (FGTS) e o Sistema Brasileiro de Poupança e Empréstimo (SBPE), que chegaram a atingir um montante bastante significativo para o investimento habitacional (BRASIL, 2004, p. 9)

O Estado brasileiro revolucionou o mercado imobiliário com a ideia de financiamento de moradia, desenvolvendo um sistema coordenado e gerido pelo BNH que usava como mecanismo para o financiamento de habitação o Fundo de Garantia de Tempo de Serviço FGTS e o Sistema Brasileiro de Poupança e Empréstimo - SBPE. No entanto, os projetos implantados durante o regime militar foram marcados pela falta de compromisso com as populações de baixo poder aquisitivo. Privilegiou-se, neste cenário, as populações de médio e alto poder aquisitivo, denotando um caráter seletivo e restritivo (BRASIL, 2004).

Com o fim do regime ditatorial, no ano de 1985, o Sistema de Financiamento Habitacional - SFH passou por grave crise, intensificando-se com a extinção do BNH no ano de 1986. As políticas habitacionais, a partir desse período, conheceram intenso imobilismo. Houve, portanto, "[...] um hiato em relação as políticas habitacionais no país, com a desarticulação progressiva da instância federal [...]" (BRASIL, 2004, p. 10).

É somente nos primeiros anos do século XXI que o Estado brasileiro demonstrou sinais de preocupações e priorizou a articulação e o desenvolvimento de políticas públicas voltadas à questão habitacional no país, sendo que estas conheceram significativa reestruturação. A questão habitacional e, no interior desta, as políticas desenvolvidas, conheceram maior efetividade, sobretudo, pelo caráter articulado. A criação do Ministério das Cidades atesta esta inquietação com uma articulação das políticas habitacionais no país.

Estes processos de reestruturação das políticas de habitação foram delineados a partir do ano de 2003, no início da gestão federal de Luiz Inácio Lula da Silva, quando foi criado o Ministério das Cidades, cuja função central se voltou ao desenvolvimento de uma política mais ampla, de modo que integrasse os segmentos sociais antes excluídos. Com isso, observa-se que a agenda orientada para o desenvolvimento da política habitacional no Brasil, antes fragmentada, passou a ter maior articulação e efetividade.

Segundo Gomes (2016, p. 39) "[...] o órgão foi designado para promover condições para articulação das políticas urbanas, com a contribuição da sociedade, visando 
Uma Cidade para Poucos? Particularidades da produção da moradia para segmentos populares em...

desenvolver a produção sustentável do espaço urbano". Nessa direção, Cardoso e Aragão (2013, p. 32) reforçam:

O cenário de crescimento econômico que se desenha a partir de então irá ter reflexos na redução dos indicadores de pobreza e desigualdade resultado, em parte dos programas de transferência de renda (o Bolsa Família), em parte da elevação real do valor do salário mínimo e na emergência e consolidação da classe $C$, que passará a ser considerado um "nicho de mercado" com importância crescente, passando a fazer parte das estratégias empresariais do setor imobiliário.

A consolidação da classe C, como destacam Cardoso e Aragão (2013), muito contribuiu para o desenvolvimento das políticas habitacionais no Brasil a partir de 2003. No que tange à participação do setor imobiliário, os segmentos sociais vinculados a esta classe não constituíram antes objeto de preocupação por parte do Estado. É a partir desse novo cenário que teremos uma maior ampliação das políticas habitacionais no Brasil.

Associada à expansão da economia brasileira, ressalta-se as influências do Programa de Aceleração do Crescimento - PAC, desenvolvido pelo governo do Presidente Luís Inácio Lula da Silva, no ano de 2007. No conjunto de metas estabelecidas pelo PAC, destacaramse três eixos centrais: investimentos em infraestrutura, objetivando maior mobilidade das populações (construção e reformas de aeroportos, rodovias e hidrovias); energia (geração de energia elétrica, transmissão e combustíveis naturais renováveis) e as questões urbanas/sociais (saneamento básico, mobilidade urbana e habitação) (BRASIL, 2004).

As medidas adotadas no âmbito do PAC envolveram diretamente o setor imobiliário. No ano de 2009, período em que o país previa problemas gerados em face da crise econômica global difundida a partir dos Estados Unidos, foi introduzido no país por meio do PAC o Programa Minha Casa Minha Vida, importante componente da atual política habitacional. Ao considerar as influências desta política, Cardoso e Aragão (2013, p. 36) enfatizam:

\footnotetext{
Buscou-se estabelecer um patamar de subsídio direto, proporcional à renda das famílias. Este Programa busca impactar a economia através de efeitos multiplicadores gerados pela indústria da construção civil. O PMCMV é subdividido em três faixas e para cada faixa há um público particular. A faixa 1 destina-se às pessoas que dispõem de até 3 salários mínimos. A faixa 2 é voltada para às populações cujo os rendimentos alcançam até 5 salários mínimos e a faixa 3 é destinada aos trabalhadores/as que dispõem de 3 até 10 salários mínimos.
}

O Estado, portanto, promoveu o acesso ao crédito a distintos atores, priorizando neste cenário os segmentos sociais de baixo poder aquisitivo de um lado e também motivando os demais segmentos sociais. Essas medidas também objetivaram promover a difusão do setor imobiliário, aquecendo as atividades vinculadas à construção civil. 
É reconhecido que a distribuição de créditos às distintas classes sociais promoveu maior inserção da classe $\mathrm{C}$ no mercado imobiliário, estratégia essencial para enfrentar a crise econômica de 2008, que assolava tanto os países centrais como também os periféricos, buscando, desse modo, envolver segmentos de baixo poder aquisitivo.

Mesmo reconhecendo os esforços e todos avanços no desenvolvimento das políticas habitacionais no Brasil desde 2003, muitos problemas surgiram nesse processo, resultando, desse modo, em intensas críticas severas ao PMCMV, sobretudo por parte do Fórum da Reforma Urbana e dos movimentos sociais que, historicamente, têm lutado a favor da moradia no país. No conjunto destas críticas, Cardoso e Aragão (2013, p. 44) destacam:

[...] a falta de articulação do programa com a política urbana; a ausência de instrumentos para enfrentar a questão fundiária; os problemas de localização dos novos empreendimentos; excessivo privilégio concedido ao setor privado; a grande escala dos empreendimentos; a baixa qualidade arquitetônica e construtiva dos empreendimentos; a descontinuidade do programa em relação ao SNHIS [Sistema Nacional de Habitação Interesse Social] e a perda do controle social sobre a implantação.

Portanto, os privilégios concedidos aos incorporadores imobiliários e ao setor da construção civil se apresentam como motivo das críticas direcionadas ao PMCMV. Haja visto que o solo urbano na cidade capitalista contemporânea tem agregado valores significativos, sobretudo, por conta do preenchimento das áreas centrais. Araújo (2017, p. 150) a este respeito afirma que "[...] a lógica capitalista de produção do espaço urbano não é para todos, a moradia, apresenta-se como mercadoria de difícil acesso para a classe trabalhadora".

No âmbito do PMCMV, a provisão de habitações para segmentos populares é marcada pelos interesses das grandes empresas imobiliárias. Como o solo urbano nas áreas centrais das cidades é mais caro, a opção é a de procurar áreas cada vez mais afastadas das áreas centrais, onde o valor da terra urbana é mais barato. Assim, a segregação socioespacial urbana manifesta-se como elemento inerente a este processo de apropriação da cidade.

O nosso ponto de partida, neste processo analítico dos efeitos da política habitacional contemporânea difundida no espaço urbano de Imperatriz, leva em consideração os significados e os conteúdos da segregação espacial urbana, que se reflete, de forma inicial, por meio da segregação residencial. Nesse contexto, Corrêa (2013, p. 42-43) assevera que a segregação residencial da/na cidade capitalista:

[...] emerge a partir da localização diferenciada no espaço de distintas classes sociais e suas frações. Admitimos assim, que quanto mais intensa a fragmentação social, mais complexa será a segregação residencial. [...] A segregação residencial pode ser considerada, de um lado, como 
Uma Cidade para Poucos? Particularidades da produção da moradia para segmentos populares em...

autossegregação e, de outro, como segregação imposta e segregação induzida.

Neste estudo, consideramos como viés analítico, para entender os significados da política habitacional difundida a partir do PMCMV nos conjuntos habitacionais Itamar Guará I e II, a segregação residencial imposta, haja vista que o conjunto habitacional pesquisado não constituiu uma escolha da sua população. Trata-se de um espaço escolhido pelo Estado em consonância aos interesses do capital. Conforme Corrêa (2013, p. 43), a segregação imposta envolve "[...] aqueles que residem onde lhes impõem uma moradia, sem alternativas de escolha locacional e do tipo de habitação".

Em razão do exposto, apresentar-se-á, a seguir, algumas contribuições dos conteúdos e efeitos da política habitacional contemporânea desenvolvida por meio do Programa Minha Casa, Minha Vida, na cidade de Imperatriz. Neste percurso analítico, manifestou-se como inquietação central a necessidade de compreender os significados desta política e suas relações com problemática da segregação espacial urbana presente na cidade de Imperatriz, em particular no conjunto habitacional Itamar Guará I.

\section{A CIDADE PARA POUCOS? SIGNIFICADOS DA POLÍTICA HABITACIONAL NA CIDADE DE IMPERATRIZ-MA E SUAS RELAÇÕES COM A SEGREGAÇÃO ESPACIAL URBANA}

"A temática da segregação residencial possibilita, como qualquer outra temática, diversas abordagens, envolvendo matrizes teóricas distintas, assim como inúmeros temas específicos" (MAIA, 1994, p. 64).

A segregação espacial presente no espaço urbano apresenta múltiplos significados, sendo que a sua gênese pode ser notada em razão do uso distinto e desigual do espaço urbano. Corrêa (1989) na década de 1970, reconhecia este fenômeno como um processo espacial típico da cidade capitalista hodierna. Para este geógrafo, o processo de segregação na cidade, enquanto processo espacial, refere-se:

[...] à questão residencial, relacionando-se mais à reprodução da força de trabalho. A segregação é um processo espacial que origina a tendência a uma organização espacial em áreas de forte homogeneidade social interna e forte disparidade social entre elas. Estas áreas segregadas tendem a apresentar estruturas sociais que podem ser marcadas pela uniformidade da população em termos de renda, status ocupacional, instrução, etnia. [...] As diferenças sociais entre estas áreas uniformes, devem-se essencialmente ao diferencial de capacidade que cada grupo social tem em pagar pela residência que ocupa (CORRÊA, 2001, p. 132, grifo do autor).

Tem se ampliado, no Brasil, sobretudo nas últimas décadas, o volume de estudos teóricos e empíricos envolvendo a questão da segregação socioespacial urbana, 
ressaltando-se, nesse cenário, a problemática da segregação residencial. O país testemunha, desde 1950, novas formas de habitação, cujos conteúdos revelam o modo particular de organização da sociedade no tecido urbano. Há novos padrões residenciais que asseveram as novas formas de apropriação do espaço urbano.

Desde a difusão do conceito pela escola de Chicago, nas primeiras décadas do século XX aos dias atuais, é fato inconteste o reconhecimento das novas formas de habitar a cidade. Harvey (1980) e Castells (2000) ressaltam que, para compreender o diferencial residencial, importa reconhecer o processo de estruturação das classes sociais no espaço.

Ao considerar a perspectiva de interpretação da segregação espacial urbana, Frey e Duarte (2006, p. 110) enfatizam que "[...] a segregação socioespacial tem sido analisada como indicativo de agrupamentos humanos desfavorecidos no âmbito de um conjunto social - seja por questões raciais, por questões religiosas ou econômicas, esta última com especial destaque na realidade urbana brasileira". Assim, baseando-se nas ideias de Frey e Duarte (2006), as questões socioeconômicas denotam, ao mesmo tempo, a porta de acesso e os muros impostos de direito à cidade e aos bens que o espaço urbano dispõe, contribuindo, assim, para diferenciar e separar as classes sociais no espaço urbano. Negri (2008, p. 148), por sua vez, entende a segregação como "[...] um fenômeno espacial, partindo do pressuposto que é a desigual distribuição das classes que agravam as desigualdades sociais".

Acredita-se que a segregação socioespacial se configura a partir do uso diferenciado e segmentado do solo urbano. Considera-se, para efeitos de análise, o caráter desigual da apropriação do espaço urbanos pelos distintos sujeitos que habitam a cidade. Os processos de fragmentação do tecido urbano têm contribuído para explicar as dinâmicas do processo espacial da segregação residencial na cidade capitalista. Esta desigual distribuição das classes, como aponta Negri (2008) "agrava as desigualdades sociais".

Com base nesses fatos, pode-se notar no espaço as distintas formas de apropriação da cidade. Dito isto, a construção de moradias para segmentos populares se insere no conjunto destas dinâmicas. Corrêa (1989) em sua obra, O espaço urbano, discorre sobre padrões de segregação residencial (classe de baixo poder aquisitivo) que é involuntária, pois o indivíduo é submetido a ações exteriores a ele e a autossegregação (classe dominante). $\mathrm{Na}$ cidade de Imperatriz, temos evidências destes modelos, conforme expressam as imagens que seguem (figuras 2 e 3 ).

Nota-se, com base nas imagens antes expostas, que em uma mesma zona ou porção da cidade de Imperatriz é possível observar as marcas da segregação residencial, denotando, deste modo, os diferenciais e as desigualdades no uso do solo urbano pelos atores sociais. 
Figura 2 - Edifício $5^{\mathrm{a}} \mathrm{Av} . /$ bairro Bacuri

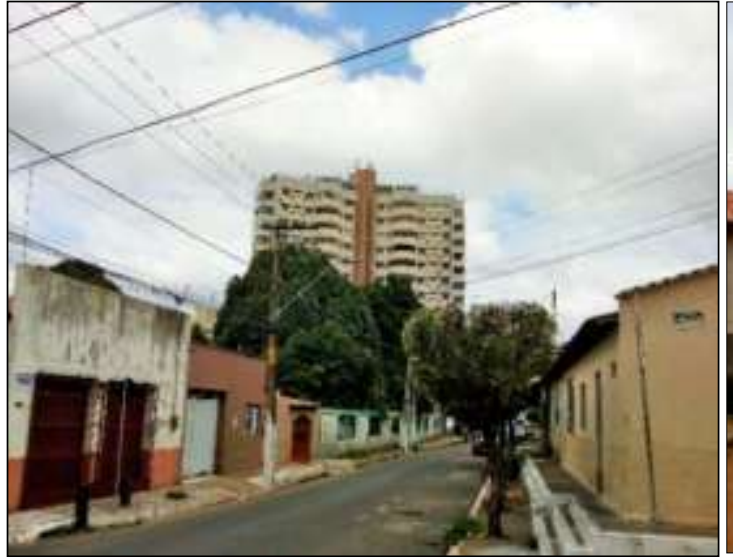

Fonte: Silva e Sousa (2019).
Figura 3 - Rua Nova/bairro Caema

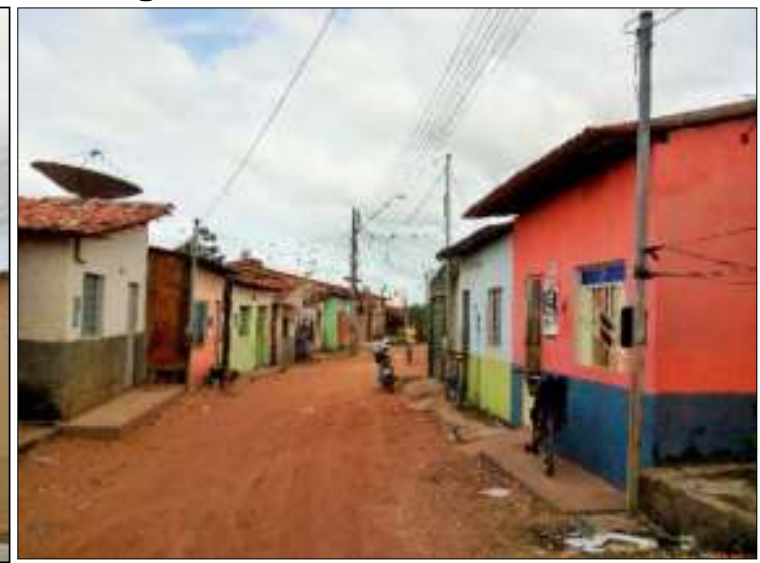

Fonte: Silva e Sousa (2019).

Diante do exposto, considera-se como fundamental o desenvolvimento de políticas públicas habitacionais eficazes, a fim de mitigar as desigualdades socioespaciais presentes no espaço urbano, uma vez que têm se sobressaído os interesses dos agentes econômicos em detrimento das necessidades das populações.

Os casos envolvendo a política habitacional recente desenvolvida em Imperatriz asseveram estas assertivas, uma vez que as políticas implementadas têm contribuído para intensificar as desigualdades socioespaciais urbanas, favorecendo a difusão da segregação espacial urbana. Com base nesses fatos, serão apresentadas, a seguir, reflexões sobre a materialidade da política habitacional orientada pelo PMCMV, tendo como recorte espacial, o conjunto habitacional Itamar Guará I, implantado nesta cidade no ano de 2012.

\section{SIGNIFICADOS DA POLÍTICA HABITACIONAL CONDUZIDA PELO PMCMV NA CIDADE DE IMPERATRIZ: UMA MATERIALIZAÇÃO DA SEGREGAÇÃO ESPACIAL URBANA?}

O conjunto habitacional Itamar Guará I encontra-se localizado às margens da rodovia Belém-Brasília (BR-010) e da Ferrovia Norte Sul. Situa-se em uma área periférica da cidade de Imperatriz, ou seja, na porção sul desta cidade, tendo sido implantado no ano de 2012 , fruto das políticas orientadas pelo PMCMV (figura 4).

O Conjunto Habitacional Itamar Guará I (figura 05) foi entregue às populações beneficiárias no ano de 2012, contando o registro de 500 famílias beneficiadas pela política habitacional do PMCMV. Para compreender a natureza e os significados da política habitacional aí desenvolvida, foi direcionado um roteiro de entrevistas que alcançou o quantitativo de 40 famílias.

Vale ressaltar que mesmo considerando o elevado número de moradores neste conjunto habitacional, optou-se por trabalhar com a pesquisa de natureza qualitativa, 
amparados nas contribuições fornecidas por Brandão (2009) e Chizzotti (2003), uma vez que mais importante que quantificar os sujeitos é qualificar as suas vozes.

Figura 4 - Mapa de localização do conjunto habitacional Itamar Guará I

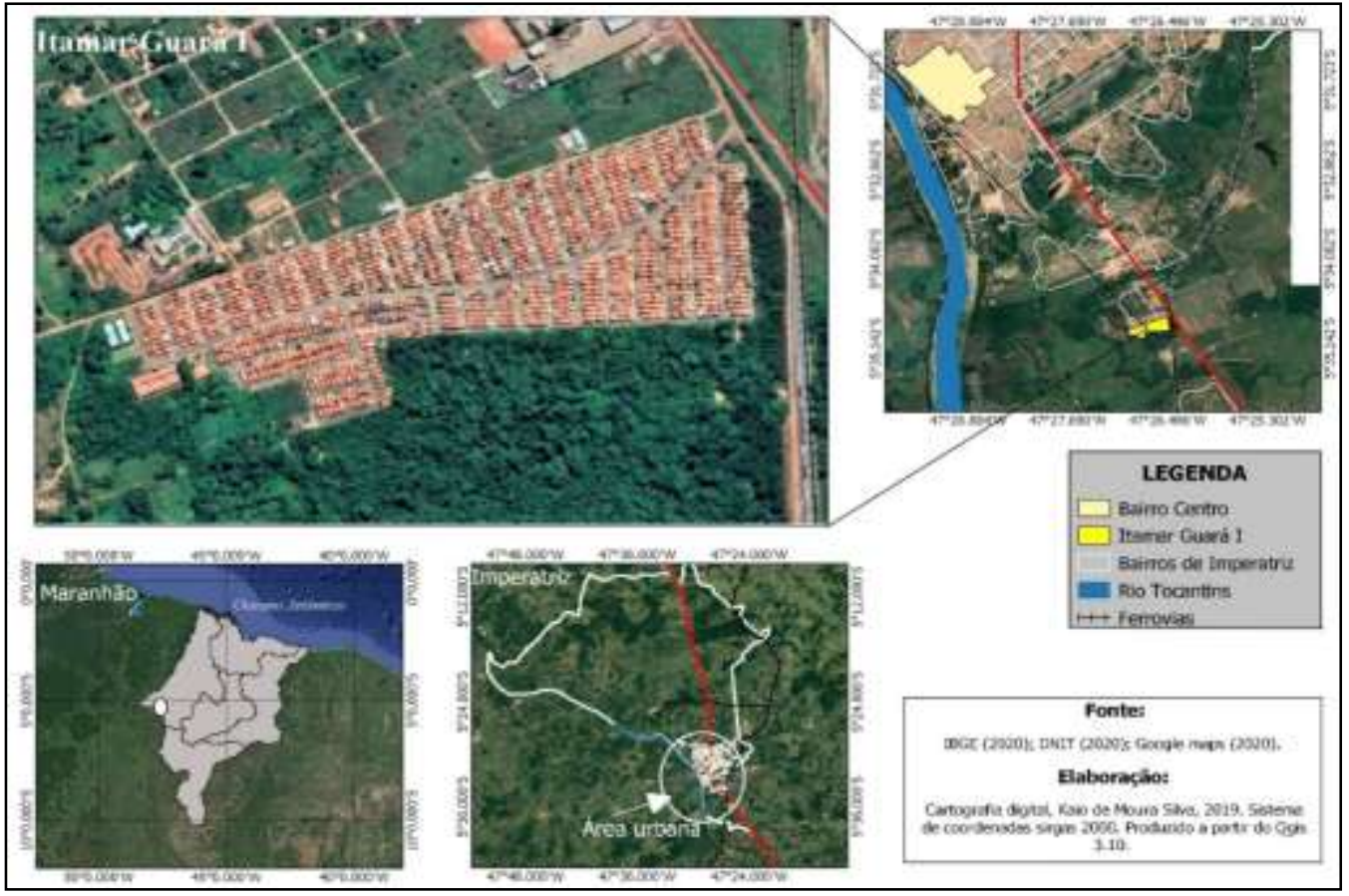

Fonte: Silva, 2020.

Figura 5 - Vista parcial do conjunto habitacional Itamar Guará

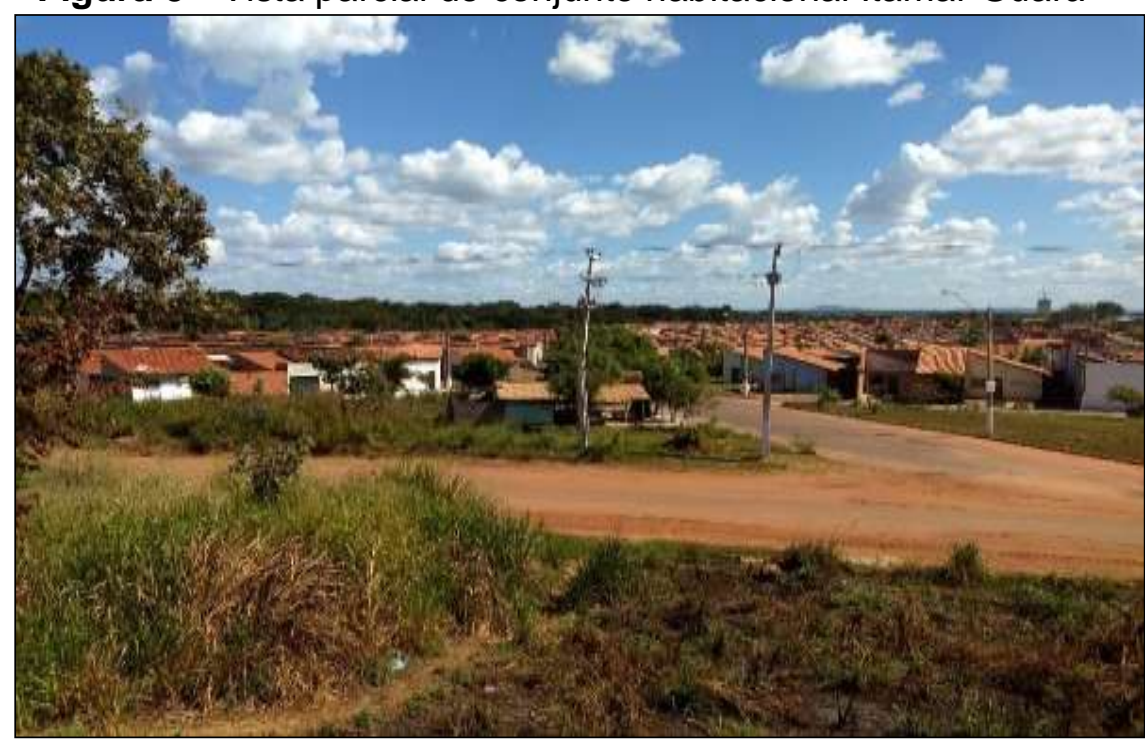

Fonte: Silva (2019).

Cumpre ressaltar que elegemos alguns elementos a fim de analisar e compreender os efeitos das políticas habitacionais desenvolvidas no conjunto habitacional pesquisado e as suas relações com as questões que envolvem a segregação espacial urbana. São eles: 
Uma Cidade para Poucos? Particularidades da produção da moradia para segmentos populares em...

- Perfil socioeconômico das populações residentes no conjunto habitacional;

- Da natureza e condições de moradia;

- Das expressões da segregação residencial e espacial urbana.

É válido enfatizar que o roteiro de entrevista apresentado aos moradores foi sistematizado em três blocos distintos, levando-se em consideração os eixos temáticos antes destacados. O primeiro e o segundo bloco se propuseram a traçar o perfil socioeconômico dos moradores, bem como compreender a percepção destes no tocante às condições de moradia no conjunto habitacional Itamar Guará I. Respostas dos moradores estão expostas a seguir.

Tenho 43 anos e trabalho como pedreiro. A minha média salarial mensal é de um salário mínimo e não terminei o ensino fundamental. As coisas são muito difíceis, questão do acesso ao mercado e outras coisas. O conjunto habitacional Itamar Guará não oferece condições adequadas de saneamento básico. Porém, sair do aluguel foi um impacto positivo para a minha vida, apesar do conjunto não dispor de boas condições de saúde (Morador 1, entrevista realizada em 15/06/2019).

Tenho 33 anos, sou carpinteiro e tenho renda mensal de até um salário mínimo. Não conclui o ensino fundamental. Estou satisfeito com a minha moradia aqui no conjunto, afinal, sair do aluguel foi um ponto positivo, porém, o conjunto não dispõe de saneamento básico adequado, pois não tem tratamento de água e esgoto, esses são pontos negativos (Morador 2, entrevista realizada em 15/06/2019).

Tenho 25 anos, sou mecânico, tenho renda mensal de até um salário mínimo e não conclui o ensino fundamental. Não estou satisfeito com a moradia aqui no Conjunto, porque a distribuição de água não é boa. $O$ conjunto não oferece condições adequadas de saneamento básico, 0 esgoto não funciona e quando chove os bueiros estouram e invadem as casas, esse é um aspecto negativo. Sair do aluguel foi um ponto positivo (Morador 3, entrevista realizada em 15/06/2019).

Com base nas falas dos moradores, nota-se que estes apresentam uma média de idade entre 20 e 45 anos. Dos 40 responsáveis por suas respectivas famílias que foram entrevistados, notou-se que 14 não concluíram a educação básica. No que tange à renda salarial, a maioria dispõe de renda média mensal de até 1.800 reais. Observou-se que estes moradores se enquadram no perfil priorizado pela política orientada pelo PMCMV, uma vez que se inserem na faixa 1 (CARDOSO; ARAGÃO, 2013).

Um fato incontestável exposto pelos moradores diz respeito à aquisição da casa própria. Todos enxergam como positivo o fato de terem saído do aluguel. Entretanto, elencam uma série de fatores negativos, uma vez que muitas contradições são evidenciadas na difusão da política habitacional difundida no conjunto, denotando fortes tensões e pouca 
efetividade. O descaso é percebido na paisagem urbana, como ilustrado nas imagens que seguem (figuras 6 e 7 ) e nas falas dos moradores.

Figura 6 - Esgoto a céu aberto

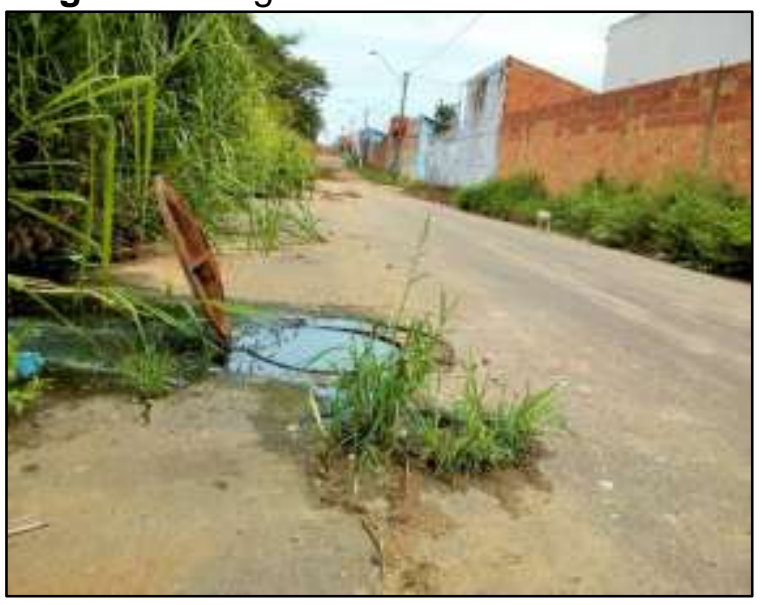

Fonte: Silva e Sousa (2019).
Figura 7 - Av. 2 no conjunto

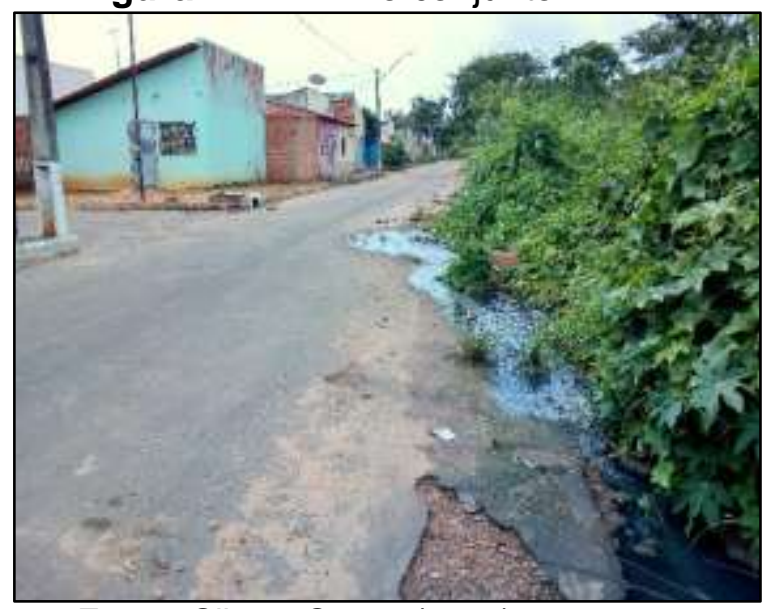

Fonte: Silva e Sousa (2019).

As imagens expostas evidenciam a precariedade e as condições deficitárias dos problemas sociais e ambientais identificados no conjunto habitacional Itamar Guará I. A ausência do saneamento básico, mesmo sendo considerado um problema comum à maioria das cidades brasileiras, revela as dimensões peculiares a esta localidade.

Becker (2005), ao estudar e refletir sobre estes problemas no cenário urbano amazônico, os classifica como uma das especificidades do urbano materializado nesta macrorregião. Imperatriz, que se localiza na porção oriental desta região, incorpora estas dimensões caóticas, pois não é uma exceção à esta regra. Para Becker (2005, p. 409), "[...] a especificidade da urbanização amazônica diz respeito às carências, inviabilizando aos citadinos condições de vida digna. Indicadores da oferta de infraestrutura urbana, condições de habitalidade e atendimento à saúde adequados expressam tais carências".

Estes elementos que envolvem a ausência de infraestrutura urbana explicam os sentidos contraditórios da reestruturação do espaço urbano na contemporaneidade, sobretudo no que se refere às populações de baixo poder aquisitivo, uma vez que estes são alijados de exercerem os seus direitos na cidade, ou seja, são negados os direitos de uma vida digna na cidade. Corrêa (1989, p. 29), a este respeito, comenta:

$\mathrm{Na}$ sociedade de classes verificam-se diferenças sociais no que se refere ao acesso aos bens e serviços produzidos socialmente. No capitalismo as diferenças são muito grandes, e maiores ainda em países como os da América Latina. A habitação é um desses bens cujo acesso é seletivo: parcela enorme da população não tem acesso, quer dizer, não possui renda para pagar o aluguel de uma habitação decente e, muito menos, comprar um imóvel. 
Uma Cidade para Poucos? Particularidades da produção da moradia para segmentos populares em...

No terceiro bloco de entrevistas, buscou-se ouvir das populações entrevistadas as formas de intervenções do poder público com relação aos seus deveres com a comunidade. Procurou-se destacar ainda as condições estruturais das moradias e o que deveria melhorar no conjunto. As entrevistas realizadas obedeceram aos mesmos critérios antes expostos.

O conjunto oferece segurança, porque existe ronda policial. Não conta com delegacia e nem posto policial. Tem ônibus, mas eu não estou satisfeito com os serviços de transporte. Os ônibus não são exclusivos para o Itamar Guará. Eles passam pelo conjunto Vitória e vila Vitória, para chegarmos até o centro da cidade. Daí as viagens se tornam mais longas, demoradas e cansativas. A estrutura da casa não está de acordo com as minhas expectativas, o material é de péssima qualidade. É péssimo reboco e a cerâmica não é de qualidade. Fui obrigado a recolocar, porque estava soltando do piso. A educação e o saneamento são as principais coisas que devem ter maior cuidado do governo. Aqui também não tem uma área de lazer, seria importante a construção. Uma delegacia também é legal para conjunto (Morador 1, entrevista realizada 15/06/2019).

O poder público oferece segurança, pois tem uma ronda policial. O conjunto conta com ônibus e estou satisfeito, pois não faltam. Não estou satisfeito é com a estrutura da casa, pois o piso no projeto era de cerâmica, porém, eu não recebi. A estrutura não foi a esperada. O saneamento básico e a segurança são os setores que devem ter mais atenção governamental. Como sugestão para a melhoria do conjunto, sugiro a construção de uma quadra de futsal e um campo de futebol, até porque não temos área de lazer (Morador 2, entrevista realizada 15/06/2019).

Existe no conjunto a ronda policial e o conjunto conta com ônibus. A estrutura da casa não está de acordo com as minhas expectativas. $\mathrm{Na}$ construção da casa não teve um bom alinhamento. Quando chove, a água acumulada na rua chega nas casas. O saneamento básico e a educação são os setores que precisam de maior atenção no conjunto. A construção de uma creche para as crianças do conjunto é a minha sugestão para a melhoria do conjunto (Morador 3, entrevista realizada 15/06/2019).

Ao se observar a fala dos moradores compreende-se o sentido caótico que tem se configurado à realidade socioespacial do conjunto. O saneamento básico é uma das principais ausências destacadas pelos moradores, configurando um grave problema.

O cenário retratado pelos moradores sobre as condições estruturais do conjunto reforça a precariedade das condições de moradia deste, reforçando, neste contexto, a problemática da segregação espacial urbana. Frey e Duarte (2006, p. 2) destacam que o "[...] fenômeno da segregação pode ser visto como um movimento de exclusão de um grupo de pessoas do seu direito à cidade [...]". No entanto, este problema pode ser o mesmo que mobilizará a sociedade à luta pelo direito à cidade (OLIVEIRA, 2017).

Por meio das vozes dos entrevistados, nota-se a necessidade de investimentos no setor educacional, mormente por conta da paralisação da construção de uma creche (figura 8). As creches são instituições importantes, pois contribuem no processo inicial de formação 
dos sujeitos e, além deste fato, possibilitam que a população esteja inserida no mercado de trabalho.

Figura 8 - Obra paralisada - construção de creche

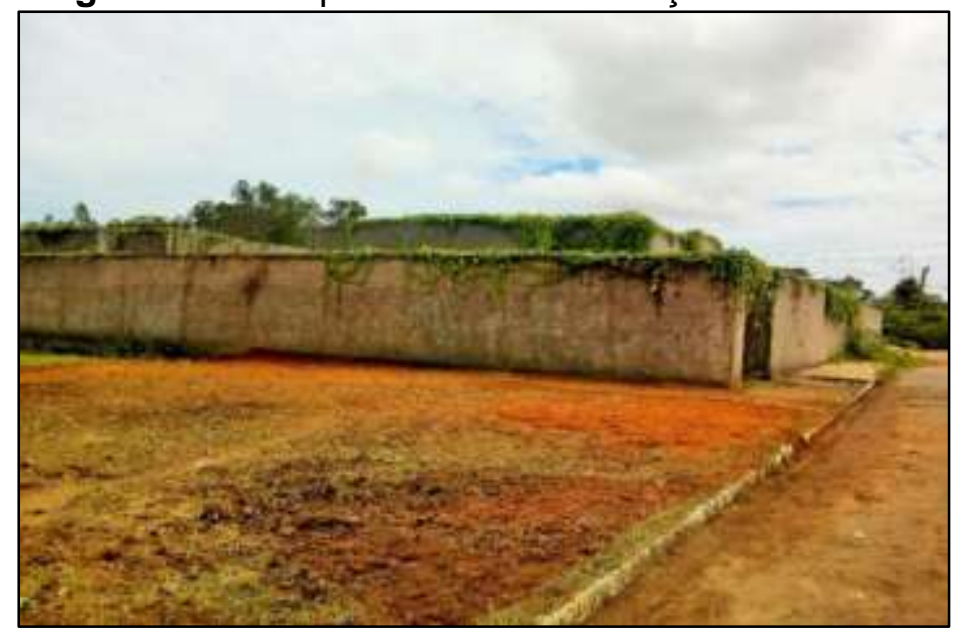

Fonte: Silva e Sousa (2019).

O conjunto dispõe de uma escola que está vinculada à rede municipal, ofertando vagas em todas as séries do ensino fundamental, porém, para estudar o ensino médio, os estudantes têm que se deslocar para outros bairros da cidade, aumentando as dificuldades de acesso à educação. Negri (2008, p. 136), a esse respeito, enfatiza:

Morar num bairro periférico de baixa renda significa muito mais do que apenas ser segregado, significa ter oportunidades desiguais em nível social, econômico, educacional, renda, etc. Um morador de um bairro periférico tem condições mínimas de melhorar socialmente ou economicamente. Implica, na maioria dos casos em apenas reproduzir a força de trabalho disponível para o capital.

Em relação aos problemas identificados no conjunto, notou-se ainda, a indignação dos moradores com relação à estrutura das casas, haja visto que tiveram que realizar reformas assim que as adquiriram, pois, o material era de péssima qualidade. As casas não alcançaram as expectativas dos moradores, tais são confirmadas nas figuras 9 e 10.

A provisão de moradias para segmentos populares, na cidade de Imperatriz, tem demonstrado claramente as formas distintas e desiguais de se habitar na cidade, uma vez que o que pesa nesse processo são as condições econômicas. Na cidade capitalista contemporânea paga-se para morar bem, em áreas que dispõem de adequada infraestrutura urbana, para aqueles que dispõem de alto poder aquisitivo. A cidade, portanto, se apresenta como espaço-mercadoria.

Cada vez mais a cidade é lugar de atuação dos agentes de produção do espaço. Uma vez humanizados, esses espaços refletirão na sua arquitetura 
e organização o padrão de desenvolvimento da complexidade das relações sociais. Este padrão ocorre por meio da segregação sócioespacial, também denominada de segregação residencial da sociedade em razão da diferenciação socioeconômica (NEGRI, 2008, p. 130).

Figura 9 - Estrutura das moradias

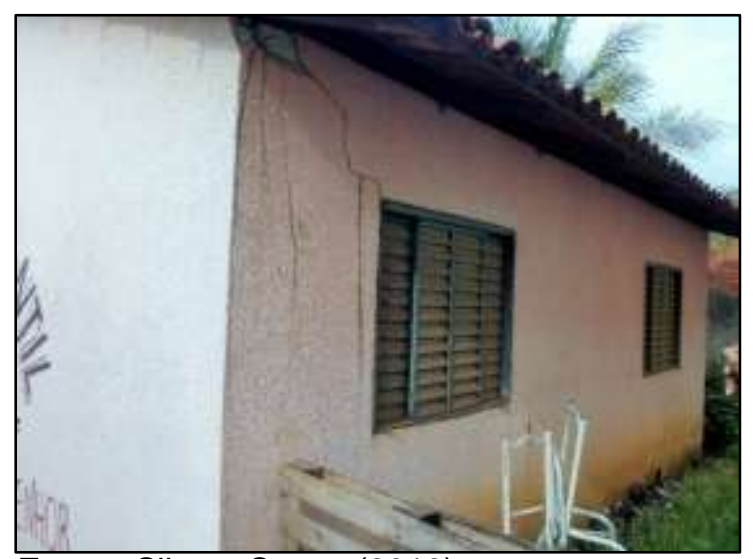

Fonte: Silva e Sousa (2019).
Figura 10 - Condições estruturais das casas

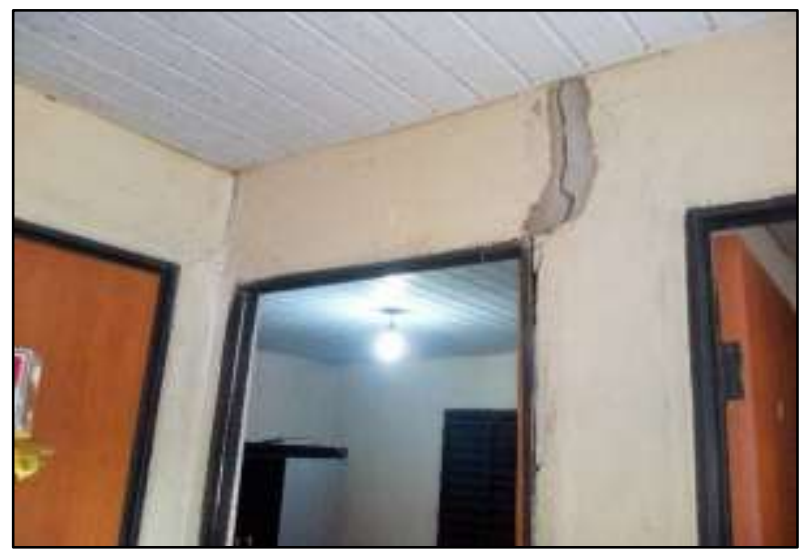

Fonte: Silva e Sousa (2019).

A diferenciação econômica promove a intensificação do processo de segregação, separando classes e negando os direitos dos cidadãos à cidade. A cidade, entendida como espaço-mercadoria se restringe a poucos que são privilegiados nesse processo, uma vez que a escolha de morar bem na cidade passa pelas condições econômicas da população. Paga-se para morar bem, só para quem dispõe de condições financeiras suficientes.

O desenvolvimento das reflexões teóricas realizadas, por meio deste estudo, associado às vozes dos entrevistados e, consequentemente, aos trabalhos empíricos realizados por meio deste estudo, asseveram o caráter fragilizado, desarticulado e ineficaz das políticas públicas de habitação, orientadas pelo PMCMV na cidade de Imperatriz.

A exemplo da sua materialidade nas demais áreas urbanas do país, compreendeu-se, por meio desta pesquisa, quão seletivas e excludentes são as políticas habitacionais difundidas neste período recente (2012-2016), em face da implantação do Programa Minha Casa, Minha Vida na cidade de Imperatriz. Sem sombra de dúvidas, esta política tem alcançado uma parcela maior da população brasileira. No entanto, o seu desenvolvimento é marcado por muitas fragilidades e pelo caráter ineficiente das gestões públicas nas distintas esferas de poder, uma vez que não atende a contento às necessidades das populações.

Com base nos fatos apresentados acerca do objeto de estudo em foco pudemos identificar o conteúdo e particularidade da política habitacional difundida na cidade de Imperatriz: as faces da segregação espacial urbana, que se radicaliza a partir das parcas condições dos serviços urbanos prestados no conjunto habitacional Itamar Guará I, entendidos como essenciais para assegurar os direitos dos cidadãos à cidade. Portanto, se 
expressa como segregação socioespacial, ou seja, em seu sentido polissêmico, como assim define Sposito (2013).

Este fato coaduna com o título deste ensaio, reforçando que a cidade tem sido produzida para poucos. Ou seja, trata-se de um processo de produção do espaço urbano que legitima os interesses de parcelas da sociedade capitalista e exclui parcelas significativas da população, uma vez que a política desenvolvida não incorpora os sentidos da moradia digna.

\section{CONSIDERAÇÕES FINAIS}

As políticas habitacionais integram relevante componente dos processos que envolvem a organização do espaço urbano por meio dos atores que são responsáveis pela produção e reprodução da cidade. Ao considerar o percurso evolutivo destas políticas no país, evidenciou-se como marcas essenciais deste fenômeno a produção desigual das cidades. Estes acontecimentos puderam ser observados, fundamentalmente, em razão de um processo espacial que é peculiar à cidade capitalista hodierna - a segregação espacial urbana.

Neste estudo teve-se como preocupação central compreender as relações e significados da recente política habitacional desenvolvida no âmbito do Programa de Aceleração do Crescimento - PAC, por meio do Programa Minha Casa, Minha Vida. Desse modo, constatou-se que tem se sobressaído os interesses econômicos em detrimento das necessidades sociais. $O$ incessante desejo pelo lucro que constitui um elemento típico das intenções da sociedade capitalista contemporânea enxerga a cidade como mercadoria.

O PMCMV, difundido na cidade de Imperatriz, e materializado no conjunto habitacional Itamar Guará I, é tributário das referidas dinâmicas, cujas dinâmicas confirmam todos os problemas que estão associados em um sentido mais restrito à segregação residencial e, num movimento mais amplo, à segregação socioespacial urbana, revelando os reais conteúdos da questão habitacional e, em particular, a problemática da moradia no país.

As reflexões teóricas, associadas aos trabalhos empíricos, expressos por meio das populações entrevistadas, confirmam a natureza fragilizada e desarticulada das políticas desenvolvidas no conjunto habitacional Itamar Guará I, denotando a falta de compromisso das gestões públicas nas distintas esferas de poder com o planejamento e gestão urbana.

Os problemas constatados, no estudo, são evidentes, conforme observou-se em relação à ausência da infraestrutura urbana que se expressa em face da falta do saneamento básico, a carência por serviços de segurança pública e os descasos com a educação. Observou-se, ainda, a despreocupação com a produção de espaços públicos de lazer para a população. Os problemas arrolados no estudo confirmam o fato de que a cidade 
Uma Cidade para Poucos? Particularidades da produção da moradia para segmentos populares em...

capitalista hodierna é pensada por poucos e para poucos. As populações residentes, neste conjunto, convivem cotidianamente como problemas sociais e ambientais que são graves e crônicos, pois são destituídos dos seus direitos à cidade.

Estes problemas revelam a necessidade urgente de se repensar as formas como estas políticas têm sido conduzidas, uma vez que elas têm contribuído cada vez mais para agudizar o apartheid social que é peculiar à realidade urbana brasileira.

\section{REFERÊNCIAS}

ARAÚJO, Luciana Medeiros de. Produção imobiliária e novas dinâmicas de expansão urbana em Patos e Cajazeiras (PB). 2017. Tese (Doutorado em Geografia) - Faculdade de Geografia, Universidade Federal da Paraíba, João Pessoa, PB, 2017.

BECKER, Bertha K. A urbe amazônida: a floresta e a cidade. Rio de Janeiro: Garamond, 2013.

BECKER, Bertha K. Dinâmica urbana na Amazônia. In: DINIZ, Clélio Campolina; LEMOS, Mauro Borges (org.). Economia e território. Belo Horizonte: UFMG, 2005. p. 401-428.

BECKER, Bertha K. Fronteira e urbanização repensadas. In: BECKER, Bertha K.; MIRANDA, Mariana H.; MACHADO, Lia O. Fronteira amazônica: questões sobre a gestão do território. Brasília: UNB; Rio de Janeiro: UFRJ, 1990. p. 1-15.

BRANDÃO, Carlos R. Prefácio. In: RAMIRES, Júlio César de Lima; PESSÔA, Vera Lúcia Salazar (org.). Geografia e pesquisa qualitativa: nas trilhas da investigação. Uberlândia: Assis, 2009. p. 15-21.

BRASIL. Ministério das cidades. Política nacional de habitação. Brasília, DF: Ministério das Cidades, 2004.

CARDOSO, Adauto Lúcio; ARAGÃO, Thêmis Amorin. Do fim do BNH ao programa minha casa minha vida: 25 anos da política habitacional no Brasil. In: CARDOSO, Adauto Lúcio. 0 programa Minha Casa Minha Vida e seus efeitos territoriais. Rio de Janeiro: Letra Capital, 2013. p. 16-65.

CASTELLS, Manuel. A questão urbana. Rio de Janeiro: Paz e Terra, 2000.

CHIZZOTTI, Antônio. A pesquisa qualitativa em ciências humanas e sociais: evolução e desafios. Revista Portuguesa de Educação, Braga, PT, v. 16, n. 2, p. 221-236, 2003.

CORRÊA, Roberto Lobato. O espaço urbano. São Paulo: Ática, 1989.

CORRÊA, Roberto Lobato. Os processos espaciais e a cidade. In: CORRÊA, Roberto Lobato. Trajetórias geográficas. Rio de Janeiro: Bertrand Brasil, 2001. p. 121-143.

CORRÊA, Roberto Lobato. Segregação residencial: classes sociais e espaço urbano. In: VASCONCELOS, Pedro de Almeida; CORRÊA, Roberto Lobato; PINTAUDI, Silvana Maria (org.). A cidade contemporânea: segregação espacial. São Paulo: Contexto, 2013. p. 3959.

FREY, Klaus; DUARTE, Fábio. Auto-segregação e a gestão das cidades. Revista Ciências Sociais em Perspectiva, Cascavel, PR, v. 5, n. 9, p. 109-120, 2006.

FUNDAÇÃO JOÃO PINHEIRO. Centro de Estatística e Informações. Déficit habitacional municipal no Brasil. Belo Horizonte: Fundação João Pinheiro, 2013. CD-Rom.

FUNDAÇÃO JOÃO PINHEIRO. Déficit habitacional no Brasil. Belo Horizonte: Fundação João Pinheiro, 2019. Disponível em: http://fjp.mg.gov.br/index.php/produtos-eservicos1/2742-deficit-habitacional-no-brasil-3. Acesso em: 7 jan. 2019. 
GOMES, Cristina Costa. Efeitos da política habitacional no município de Imperatriz MA: uma avaliação dos avanços e retrocessos do PMCMV no Conjunto Habitacional Itamar Guará I e II. 2016. Monografia (Graduação em Serviço Social) - Faculdade de Serviço Social, Instituto de Ensino Superior do Sul do Maranhão, Imperatriz, MA, 2016.

HARVEY, David. A justiça social e a cidade. São Paulo: Hucitec, 1980.

IBGE. Cidades. Imperatriz- MA. Rio de Janeiro, RJ: IBGE, 2019. Disponível em: http://www.cidades.ibge.gov.br/xtras/perfil.php?lang=\&codmun=210530\&search=maranhao $\mid i$ mperatriz. Acesso em: 28 out. 2019.

MAIA, Carlos Eduardo Santos. Segregação residencial o confronto entre a escola de ecologia humana e o marxismo. 1994. Dissertação (Mestrado em Geografia) Departamento de Geografia, Universidade Federal do Rio de Janeiro, RJ, 1994.

NEGRI, Sílvio Moisés. Segregação sócio-espacial: alguns conceitos e análises. Coletâneas do Nosso Tempo, Rondonópolis, MT, v. 7, n. 8, p. 129 - 153, 2008.

OLIVEIRA, Helbaneth Macêdo. Verticalização urbana e segregação socioespacial em Imperatriz-MA: uma abordagem a partir dos bairros Jardim Três Poderes e Maranhão Novo. 2017. (Mestrado em Geografia) - Universidade Federal do Tocantins, Porto Nacional, TO, 2017.

SANTOS, Milton. A nova urbanização diversificação e complexidade. In: SANTOS, Milton. A urbanização brasileira. São Paulo: Hucitec, 1996. p. 29-64.

SANTOS, Milton; SILVEIRA, Maria Laura. O Brasil: território e sociedade no início do século XXI. Rio de Janeiro: Record, 2011.

SILVA, Kaio de Moura; SOUSA, Jailson de Macedo. Configurações e significados das políticas habitacionais no município de Imperatriz: uma abordagem a partir do conjunto habitacional Itamar Guará. Imperatriz, MA: Universidade Estadual da Região Tocantina do Maranhão - UEMASUL, 2019. Relatório de pesquisa.

SOUSA, Jailson de Macedo. A cidade na região e a região na cidade: a dinâmica socioeconômica de Imperatriz e suas implicações na região Tocantina. Imperatriz: Ética, 2009.

SOUSA, Jailson de Macedo. Enredos da dinâmica urbano-regional sulmaranhense: reflexões a partir da centralidade econômica de Açailândia, Balsas e Imperatriz. Tese (Doutorado em Geografia) - Universidade Federal de Uberlândia, Uberlândia, MG, 2015.

SOUSA, Jailson de Macedo. Reestruturação urbano-regional amazônica e seus reflexos na produção do espaço urbano de Imperatriz-MA. Caderno de Geografia, Belo Horizonte, MG, v. 28 , n. 52 , p. $79-105,2018$.

SPOSITO, Maria Encarnação Beltrão. Segregação socioespacial e centralidade urbana. In: VASCONCELOS, Pedro de Almeida; CORRÊA, Roberto Lobato; PINTAUDI, Silvana Maria. (org.). A cidade contemporânea: segregação espacial. São Paulo: Contexto, 2013. p. 61 93.

Recebido: junho de 2020. Aceito: novembro de 2020. 